\title{
Gamifying Research Activity Support System
}

\author{
Shigeki Ohira \\ Nagoya University \\ Furo-cho, Chikusa-ku \\ Nagoya, Aichi, Japan \\ +81-52-789-5878 \\ ohira@nagoya-u.jp
}

\author{
Saya Sugiura \\ Nagoya University \\ Furo-cho, Chikusa-ku \\ Nagoya, Aichi, Japan \\ +81-52-789-5878 \\ ssugiura@nagao.nuie.nagoya-u.ac.jp
}

\author{
Katashi Nagao \\ Nagoya University \\ Furo-cho, Chikusa-ku \\ Nagoya, Aichi, Japan \\ +81-52-789-5878 \\ nagao@nuie.nagoya-u.ac.jp
}

\begin{abstract}
Various research activities are carried out every day in research laboratories, including conducting investigations, giving seminars on progress, performing experiments, analyzing results, and writing papers, but all of these activities involve steady, methodical work that does not produce immediate, visible results. For this reason, a mechanism to maintain motivation when research is not going well or to help students get on track with research when they have just been assigned to a laboratory could be useful. Students that have just begun their research may not yet understand how to proceed. In this research, we have developed a research activity concierge (RAC) system, which is a platform to encompass general research activities, and applied gamification to this system to keep motivation high. Furthermore, we investigated the effect of the RAC system on the action setting and motivation and analyzed operational logs to improve usability.
\end{abstract}

\section{CCS Concepts}

- Human-centered computing $\rightarrow$ Collaborative and social computing $\rightarrow$ Collaborative and social computing theory, concepts and paradigms $\bullet$ Human-centered computing $\rightarrow$ Ubiquitous and mobile computing $\rightarrow$ Ubiquitous and mobile computing systems and tools.

\section{Keywords}

Gamification; research activity; motivation; visualization.

\section{INTRODUCTION}

Research consists of various activities. It begins with surveying related research and includes giving seminars on progress, discussing future plans, programming or constructing equipment, performing experiments, analyzing results, and writing papers. However, by looking carefully at these activities, it can be seen that the everyday activities are very boring; sometimes it goes well, and sometimes it goes not so well. Often scientists must carry on without immediate visible results.

Motivation for research increases when it is on track, and the everyday tasks become more interesting. However, when it does not go as expected or when students have just been assigned to a laboratory and do not know which way to turn, it can be difficult to maintain a high level of motivation.

On the other hand, gamification - the use of game design Permission to make digital or hard copies of all or part of this work for personal or classroom use is granted without fee provided that copies are not made or distributed for profit or commercial advantage and that copies bear this notice and the full citation on the first page. Copyrights for components of this work owned by others than ACM must be honored. Abstracting with credit is permitted. To copy otherwise, or republish, to post on servers or to redistribute to lists, requires prior specific permission and/or a fee. Request permissions from Permissions@acm.org.

TEEM'16, November 02-04, 2016, Salamanca, Spain

(C) 2016 ACM. ISBN 978-1-4503-4747-1/16/11...\$15.00

DOI: http://dx.doi.org/10.1145/3012430.3012601 elements in non-game contexts $[1,2]$-has attracted enormous interest across a range of different areas. Recently, education has been gamified [3, 4]. Bodnar and Clark put game-based learning into practice in undergraduate engineering classrooms and obtained very positive results [5]. Ohira et al. incorporated gamification into seminars and found that students' motivation to speak better and argue was markedly improved [6]. González et al. proposed an intelligent tutoring system including gamification elements, which improved student achievement and enhanced learning [7].

Therefore, we have proposed a comprehensive gamification framework for general research activities [8]. Specifically, it provides a platform for recording and organizing everyday issues and tasks arising in discussion and for visualizing the results when they are applied to real actions.

In this research, we have developed a research activity concierge (RAC) system, which is a platform to encompass general research activities, and applied gamification to this system to keep motivation high. The paper will report the effect of the RAC system on action setting and motivation and the improvement in usability by analyzing operational logs.

\section{RESEARCH ACTIVITY}

In recent years, the IDC (interest driven creator) theory [9] has attracted much attention. The past learning methods and teaching methods were "examination-driven", that is, students learnt to succeed in exams. Since the beginning of the 21 st century, the learning and teaching methods have been changing to "interestdriven", that is, students study what they interested in. By studying interesting things, students can actively engage in learning. It is expected that students can become "interest-driven creators" by studying interesting things every day.

That is, it is important to engage in intellectual creation activities by being interested in the activities. Furthermore, we can say the same thing about research activities. It can be said that students do not know what kind of activity to carry out because they have not been shown a global image of research. Therefore, it is thought that research activities can be smoothly executed by preparing guidelines of research activities for such students. Therefore, first of all, it is necessary to list the activities performed in research.

Novel methods that classify learning activities have been executed until now. For the educational knowledge administration of a university, García-Peñalvo et al. defined four characteristics of learning activities, science and technology, methods, and results, and in particular classified learning activities into 22 pieces [10]. They reported that it is easy to search accumulated knowledge by subdividing the learning activities, and they are useful for knowledge administration.

In this research, we classified all research activities into 11 main activities and 100 sub-activities. We called this the research 
activity map and expressed it in the mind map format. Two teachers and one student classified the research activities and received advice and suggestions from one other teacher and ten students. We classified the research activities into the following eleven main activities.

$$
\begin{aligned}
& \text { - } \text { Gaining expertise } \\
& \text { - } \text { Deciding research themes } \\
& \text { - } \quad \text { Deciding evaluation methods } \\
& \text { - Experimentation } \\
& \text { - Project meetings } \\
& \text { - Seminar presentation } \\
& \text { - Discussion } \\
& \text { - Conference participation } \\
& \text { - Conference presentation } \\
& \text { - Writing papers }
\end{aligned}
$$

The main activities focus on the activities performed in every area of research. In our laboratory, although the main activity of "acquiring special knowledge and technology" includes the subactivity of "writing a program," if it changes according to the area of research, it can be used in other areas of research. Moreover, the main activities cover activities after a student is assigned to a laboratory until he/she graduates. We arranged activity nodes in a clock pattern on the research activity map in such a way as to be able to carry out activities in sequence.

Each activity is subdivided into simple and practicable actions according to the level of difficulty. In this research, we subdivide the main and sub-activities into about five hundred actions. For example, in the activity of "experiments conducted using human subjects," the actions at the time of the experiment of "explaining the content of an experiment" and "performing a questionnaire" and the actions after the experiment of "summarizing the result of questionnaire" are included. Moreover, the action of the subject of "participating in an experiment as a subject" is also included. Thus, by showing concretely the action to achieve a goal that should be performed in research activities, users can choose an action without omitting any actions.

Furthermore, we prepared about 240 activity results that can acquire the practice status of a target action automatically and can perform statistical assessment. In our laboratory, we use commercial software and an independently developed system. By acquiring and analyzing the usage history from each system automatically, showing a user the result of an activity, and admiring the outcome automatically produced during the activity, it is thought that the user's motivation will be improved. The activity results are quantitative, for example, in the activity of "writing a program," the results of "committed 1/5/10 times," "wrote 1/10/100 lines," and "accumulation of code passed 1000/5000/10000 lines" are prepared.

\section{RESEARCH ACTIVITY CONCIERGE}

Systems developed to support research activity include, Papits [11] for sharing information about "know-who" in a university laboratory, MIRASS [12] for improving usability of scientific search engines for medical informatics through data mashup, and systems for managing repositories of resources accumulated through research activities in a laboratory $[13,14]$.

In this research, we have developed the "research activity concierge", a comprehensive support system for general research activities, by introducing a gamification framework for organizing issues and tasks based on seminar content and visualizing research activity based on performance of the tasks. The system provides a service that supports research activities seamlessly.

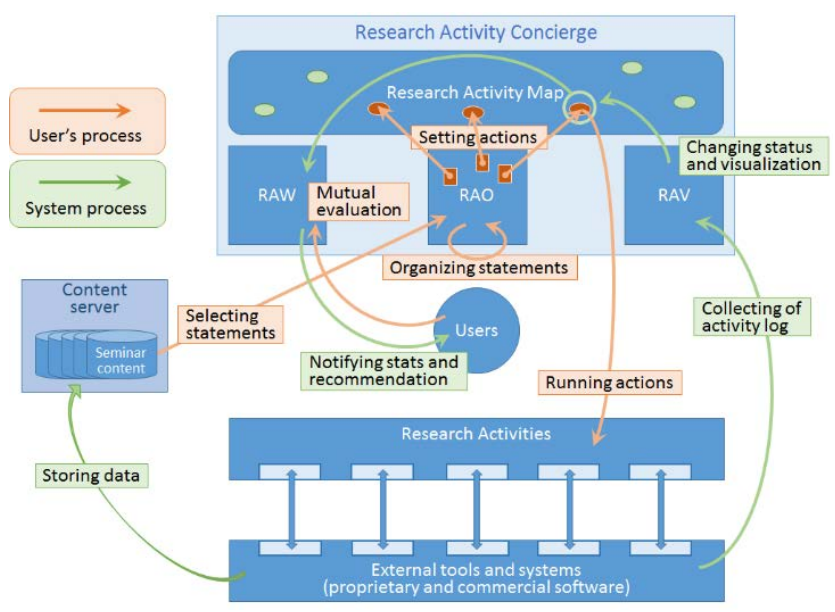

Figure 1. Research Activity Concierge system overview

As shown in Figure 1, the research activity concierge system consists of three basic tools: the research activity organizer (RAO), the research activity visualizer (RAV), and the research activity watch-dog (RAW). RAO is a tool for organizing issues and tasks based on seminar content, and RAV is a tool for visualizing research activity based on performance of issues and tasks. RAW is a tool that constantly monitors the information input and output from RAO and RAV, describes the current state to the user, and makes recommendations for action. RAO and RAV are applications that run on a web browser. In this research, since we carried out experiments and analysis using RAO and RAV, we will explain them each briefly.

\subsection{Research Activity Organizer (RAO)}

A screen shot of RAO is shown in Figure 2. The right side of the screen is statement view for browsing the content of a discussion in a seminar, and the left side of the screen is note view for organizing issues and tasks.

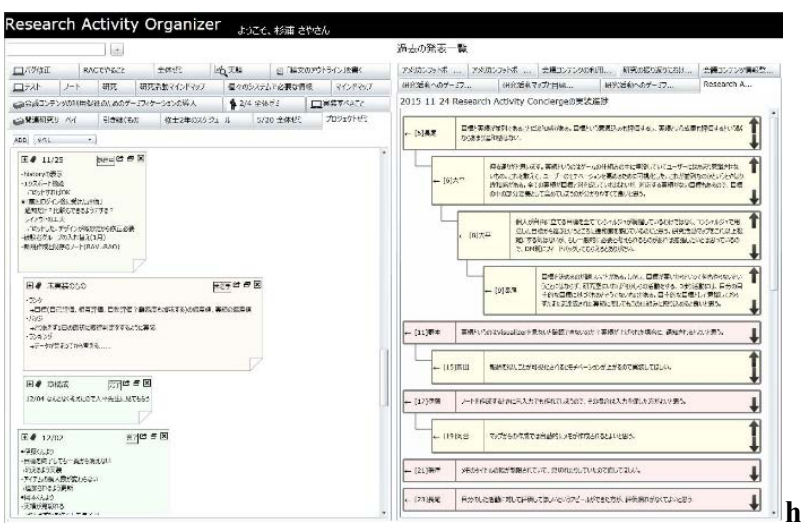

Figure 2. Research Activity Organizer 
Users organize the statements in note view, while viewing them in statement view. Users can create notes for various research activities, such as surveys, implementations, or writing papers, and record detailed information in memos. For example, they could create a note called "future necessary development" and create memos for each function to be developed.

Users can also create a note on a research activity map displayed by RAV, which we will describe later. When users choose an activity on a research activity map and click on the icon of "creating a note", a screen on the browser will transition to RAO and the created note will be displayed. It is also possible to attach four kinds of progress tags to a created memo, such as not-yet, inprogress, completed, or pending. Actions can also be selected on a research activity map and attached to memos in the form of tags. Thus, created memos can record what research activity they relate to.

\subsection{Research Activity Visualizer (RAV)}

RAV is a tool for visualizing research activity. It can visualize issues, tasks, and relationships that result from related research activities organized with RAO on a research activity map (Figure $3)$. RAV can also show the state of processing for such items quantitatively.

For this research, we used external tools and systems as much as possible for recording digital data, so that the results of practically using issues and tasks can be handled quantitatively. In our laboratory, we use both commercial software and independently developed software (Table 1). These software packages enable the recording of the number of statements in discussions, times users view seminar content, items committed in repositories, and words users input during paper writing, together with the dates and times. An API or plug-in is used to retrieve information from each external tool or system, and when the user performs a research activity based on an issue or task, an outline of the action is retrieved by RAV. The selecting of a target action from 500 actions and the confirmation of attaining one of the 240 activity results are performed and can be seen in the action and result graphs on RAV. The number of actions and results prepared by the activity is indicated on the left side of each activity node on RAV. When a user clicks on it, the corresponding graph is displayed as shown in Figure 4.

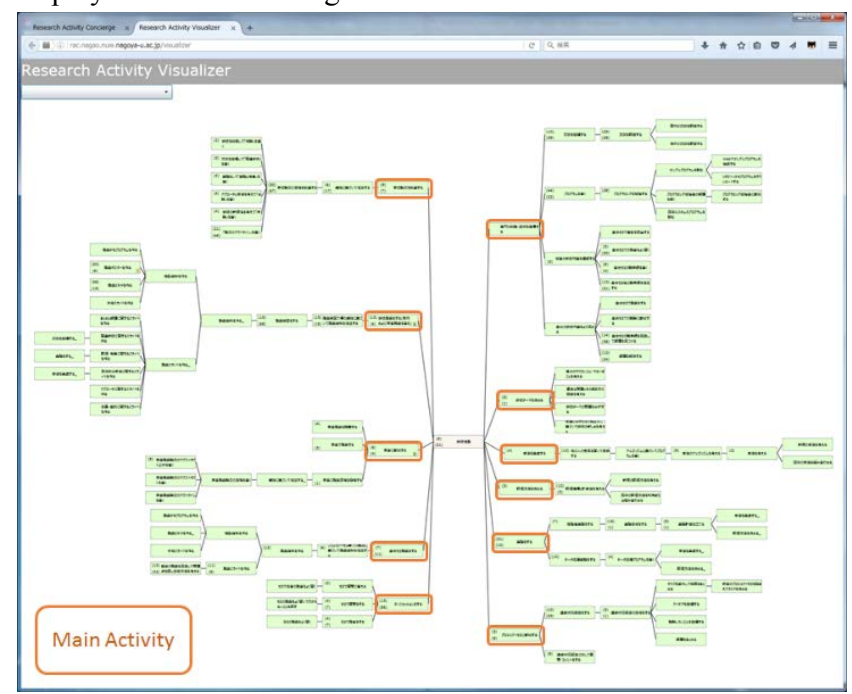

Figure 3. Research activity map on RAV
Table 1. Research Activity and Tool/System

\begin{tabular}{|c|c|}
\hline Research Activity & Tool/System Name \\
\hline \multirow{2}{*}{$\begin{array}{l}\text { Recording and Viewing } \\
\text { Seminars }\end{array}$} & Discussion Recorder \\
\hline & Discussion Browser \\
\hline Survey & TDAnnotator \\
\hline \multirow{3}{*}{ Development } & Eclipse \\
\hline & Visual Studio \\
\hline & Version Control System \\
\hline Writing paper & TDEditor \\
\hline \multirow{2}{*}{$\begin{array}{l}\text { Presentation } \\
\text { (and training) }\end{array}$} & Microsoft PowerPoint \\
\hline & Presentation Practice \\
\hline \multirow{2}{*}{$\begin{array}{l}\text { Summarizing } \\
\text { experiments and analysis }\end{array}$} & Microsoft Excel \\
\hline & Content Server \\
\hline
\end{tabular}
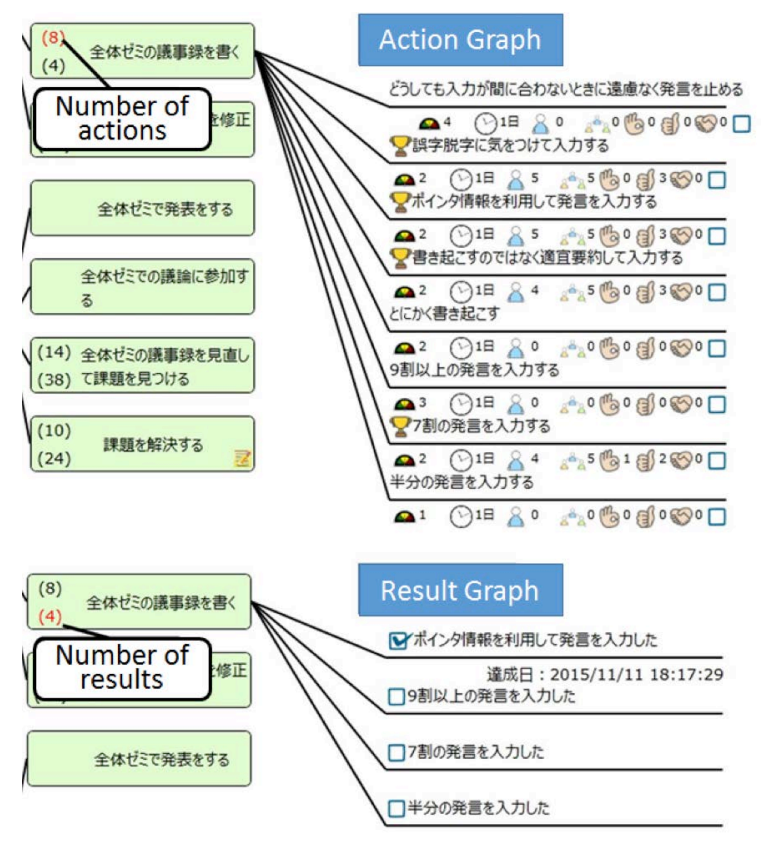

Figure 4. Action and Result Graph

\section{APPLICATION OF GAMIFICATION TO RAC}

The gamification framework for research activities is shown in Figure 5. This framework has eight elements [8]: "goals", "rules", "visualization", "design", "social”, "tutorial”, "difficulty adjustment", and "play cycle." In this research, we applied three elements of goals, rules, and visualization to RAC.

\subsection{Goals}

Users set up simple and practicable goals obtained by subdividing research activities and perform daily research activities. This system uses actions that subdivided each activity into the level of issues and tasks as described in Section 2. 
Users use RAV for setting up a goal. Users choose the activity that should be performed on the research activity map. If a user clicks a numeric value at the upper left of an activity node, the action graph will be displayed, and the user can see the list of actions prepared by the activity. Under each action name, the difficulty level, standard required number of days, the average score of self-assessment, the highest score of mutual evaluation, and the number of stamps received from others are displayed from the left. When a user selects an action from the action graph, a pop-up window, as shown in Figure 6, will be displayed. In this window, the user inputs the required number of days to finish the action. By setting up the required number of days, the user can understand at a glance which action should be performed preferentially. Moreover, when an action is finished in fewer days than the number of required days, the experience point increases as a bonus. On the research activity map, the activity node to which the goal is set is highlighted red.

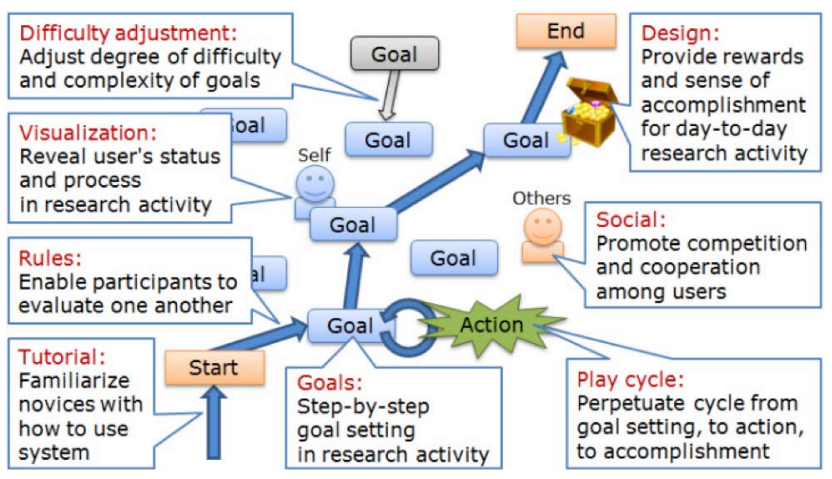

Figure 5. Gamification Framework for Research Activity

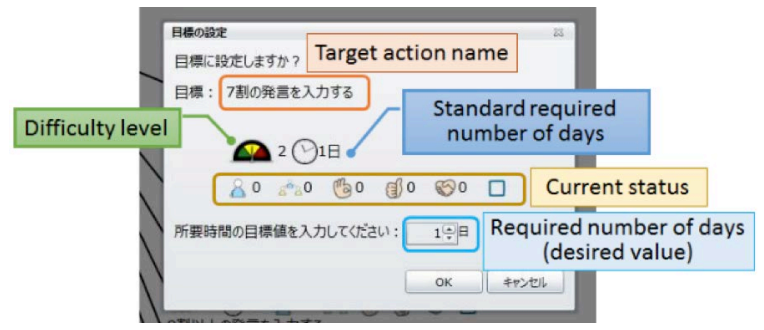

Figure 6. Configuration screen for goal setting

\subsection{Rules}

The rule element provides a method of evaluation for goals. The three methodologies of self-assessment, mutual evaluation, and automatic estimation evaluate the target action.

Self-assessment means that the user evaluates his/her own actions on a five-point scale. Since it is difficult to judge by computer whether a goal has been achieved depending on the activity, in this system, it is considered that the user has finished the target action by performing self-assessment. A screenshot of selfassessment is shown in Figure 7.

Mutual evaluation means getting a user's action evaluated by other users. Two indicators exist in mutual evaluation. One is a stamp assessment. This is not being concerned with the content of activity, but getting the activity itself evaluated. There are three types of stamp: "Like!", "Great!", and "Thanks!" A screenshot of mutual evaluation is shown in Figure 8, and the type of stamp is shown in Figure 9.

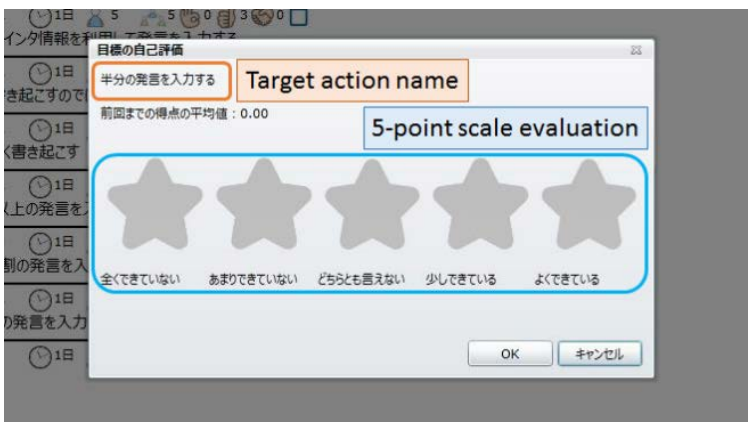

Figure 7. Screenshot of self-assessment

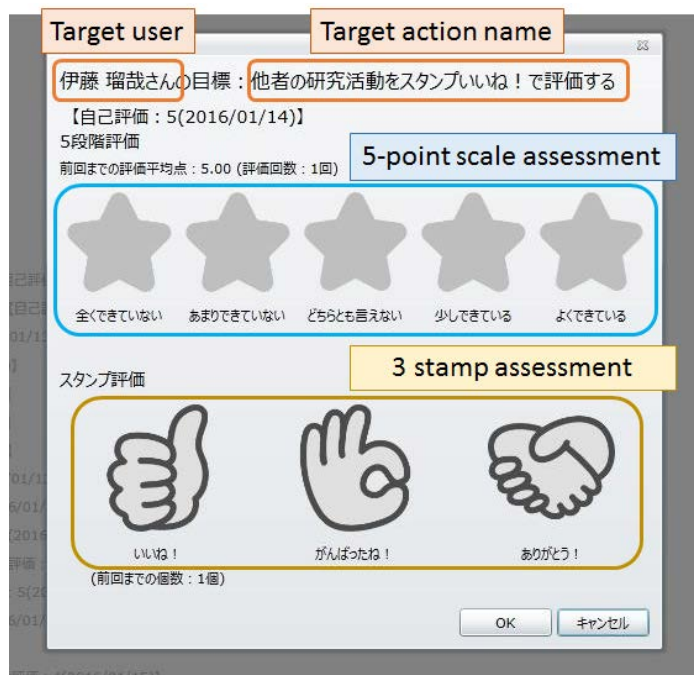

Figure 8. Screenshot of mutual evaluation

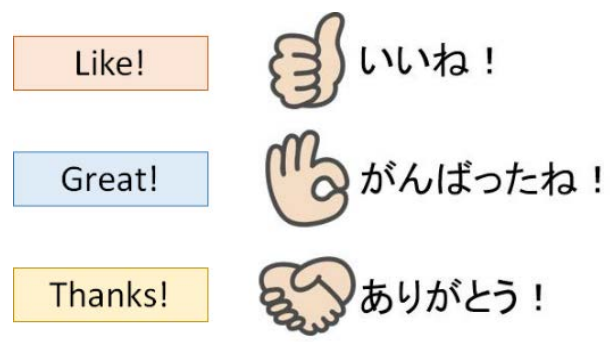

Figure 9. Three types of stamp

The other indicator is a five-point scale assessment. The stamp assessment evaluates the activity itself, and a five-point scale assessment is used to evaluate the content of activity. Mutual evaluation becomes possible after a user finishes self-assessment.

Automatic estimation is utilizing the usage history of the tool/system used for each research activity and judging the target action mechanically to get the activity result. In automatic estimation, the system judges using only the quantitative evaluation of the action. Moreover, to use a tool/system for some but not all actions, automatic estimation is carried out only for a goal that can be achieved and judged mechanically. For example, in the main activity of "discussion", since metadata is recorded by discussion recorder, the action about the frequency of utterances of "making remarks once" and the action "to acquire agreement" can be judged mechanically. 


\subsection{Visualization}

The visualization element provides the Web page that can confirm the achievement status of goals, the number of activity results gained, etc.

In the top page (Figure 10), the user can confirm the list of the achievement status of actions and results that he/she and other users have set up. Moreover, users can confirm the mutual evaluation etc. that was received after the last login. In addition, users can see the status, such as level, experience, rank, coin, badge, item, and mission (one part is in trial use).

On the status page (Figure 11), users can confirm the number/fraction of achievements for actions and results and the status for every main activity in the research activity map. Moreover, the graphical representation of the detailed information, such as the accumulation of the action numbers attained in one week, and the total number of stamps "given to/received from" the other users in the mutual evaluation is shown. Thereby, in all research activities, users can confirm which activity has been performed a lot and which activity has not been performed enough.

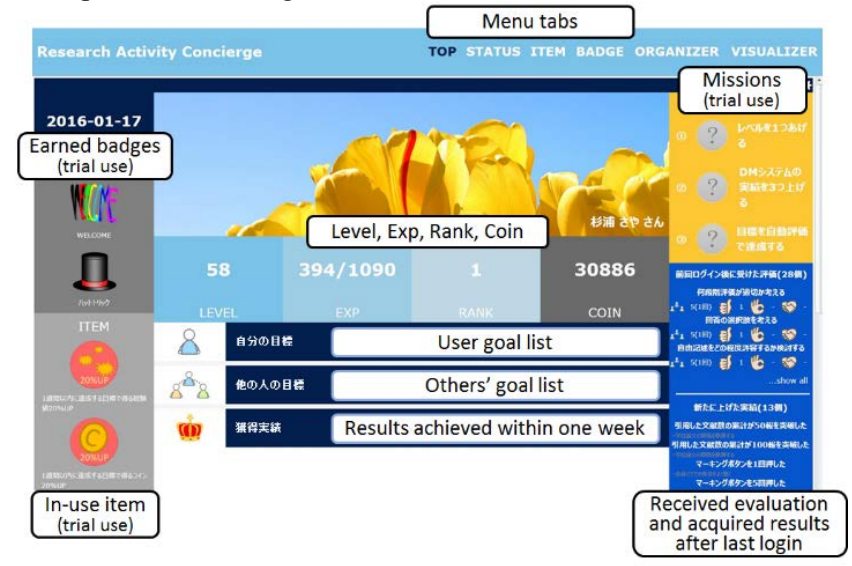

Figure 10. Top page of RAC

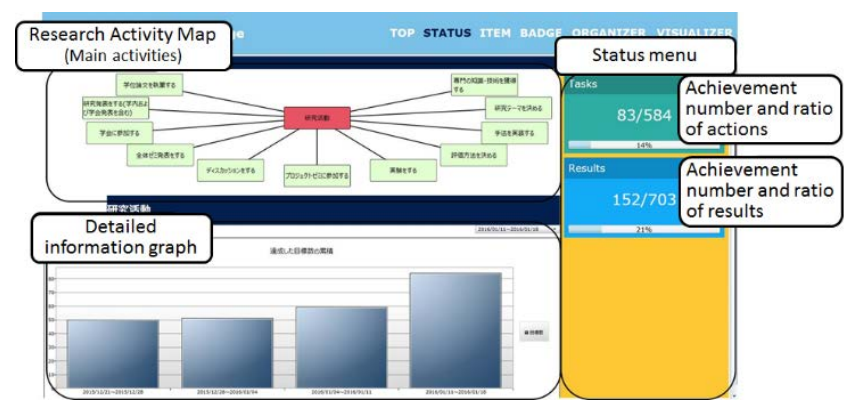

Figure 11. Status page of RAC.

\section{EXPERIMENTS AND ANALYSIS}

\subsection{Analysis of Goal Setting and Motivation}

To assess the effectiveness of the proposal system and gamification, we conducted experiments. Specifically, we investigated the effect of the arrangement of issues and tasks by RAO and the visualization of the mutual evaluation and the automatic estimation on goal setting and motivation. The subjects that participated in the experiments ranged from undergraduate seniors (B4) to second year graduate students (M2). There were ten students (B4: five students and M1 and above: five students) in our laboratory (Table 2). Regarding with/without RAO, with/without visualization of mutual evaluation, and automatic estimation, we analyzed, based on the activity logs, what kind of difference arises in the status of goal setting, self-assessment, and activity results. The experimental period was about one month from November 24 to December 31, 2015.

Table 2. Subject group

\begin{tabular}{|l|c|c|c|}
\hline \multicolumn{2}{|c|}{} & \multicolumn{2}{c|}{ RAO } \\
\cline { 3 - 4 } \multicolumn{2}{|c|}{} & Used & Not used \\
\hline \multirow{2}{*}{$\begin{array}{l}\text { Mutual } \\
\text { evaluation } \\
\text { and automatic } \\
\text { estimation }\end{array}$} & Yes & $\begin{array}{c}3 \text { students } \\
\mathrm{A}[\mathrm{M}], \mathrm{C}[\mathrm{B}], \mathrm{E}[\mathrm{B}]\end{array}$ & $\begin{array}{c}3 \text { students } \\
\mathrm{F}[\mathrm{M}], \mathrm{G}[\mathrm{M}], \mathrm{J}[\mathrm{B}]\end{array}$ \\
\cline { 2 - 4 } & No & $\begin{array}{c}2 \text { students } \\
\mathrm{B}[\mathrm{M}], \mathrm{D}[\mathrm{B}]\end{array}$ & $\begin{array}{c}2 \text { students } \\
\mathrm{H}[\mathrm{M}], \mathrm{I}[\mathrm{B}]\end{array}$ \\
\hline
\end{tabular}

([B] : B4, [M] : More than M1)

First, to compare with/without RAO, we examined the number of action settings and the rate of self-assessment. The average for the group is shown in Table 3, and every student's result is shown in Figure 12. From this result, in both B4 and all, the group using RAO had the number of action settings and a high rate of selfassessment. A t-test showed the difference between two groups regarding the action settings at a significance level of $\alpha=0.05$. Moreover, we found that the user of RAO is performing more activities. Figure 13 shows the number of action settings and achieved results for every student. Furthermore, from the questionnaire, the opinion that motivation was improved by RAO was acquired for groups B4 (C, D, and E).

Table 3. Number of action settings and percentage of selfassessment (each group)

\begin{tabular}{|c|c|c|c|}
\hline \multirow{2}{*}{ Group } & RAO & $\begin{array}{c}\text { Number of } \\
\text { action settings }\end{array}$ & $\begin{array}{c}\text { Percentage of } \\
\text { self-assessment }\end{array}$ \\
\hline \multirow{2}{*}{ B4 } & Used & 56.3 & $88 \%$ \\
\cline { 2 - 4 } & Not used & 15.0 & $74 \%$ \\
\hline $\begin{array}{c}\text { More than } \\
\text { M1 }\end{array}$ & Used & 40.5 & $45 \%$ \\
\cline { 2 - 4 } All & Not used & 13.3 & $58 \%$ \\
\cline { 2 - 4 } & Used & 50.0 & $71 \%$ \\
\hline \multirow{2}{*}{ Not used } & 14.0 & $65 \%$ \\
\hline
\end{tabular}




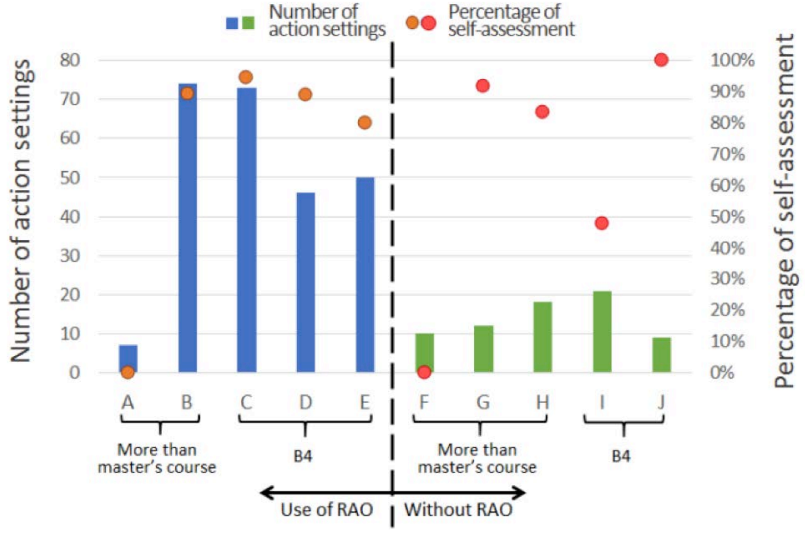

Figure 12. Number of action settings and percentage of selfassessment (each subject)

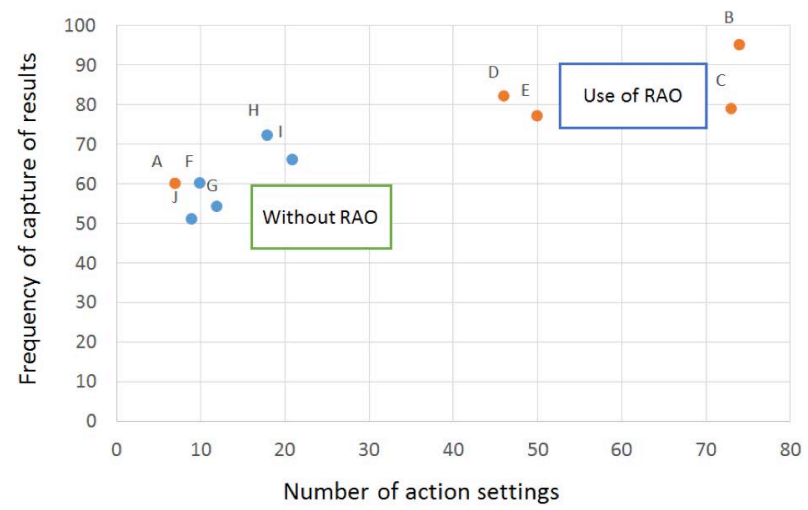

Figure 13. Number of action settings and results

Next, to compare with/without visualization of mutual evaluation and automatic estimation, we investigated the number of action settings and the rate of self-assessment. As a result, regarding B4, there is a tendency for the groups who visualized the results of mutual evaluation and automatic estimation to have a high number of action settings and a high rate of self-assessment, but there is no significant difference. From the questionnaire, four students (C, E, G, and J) answered that activity was promoted by visualization of mutual evaluation among six students who saw the result of mutual evaluation and automatic estimation. However, we found that there is concern that motivation falls conversely by performing a mutual evaluation of the action with low self-assessment. Moreover, we also found that there are some matters, such as impatience due to seeing other users' activity, methodology, and timing that present a mutual evaluation result effectively.

\subsection{Analysis of Gamification and User Interface}

We used a questionnaire to conduct a survey on gamification and the user interface.

First, as a result of answering the question "whether the gamification was effective in promoting research" in five levels, we found that $70 \%$ of users felt it was effective, but $20 \%$ of users did not think it was effective. There were some users who felt interest due to introducing the game elements, and they said that "I start to like the idea of achieving a goal" and "I was happy to increase my level," as affirmative opinions. On the other hand, we found that there were users who thought that it was not effective because of the low usability said "the goal setting was troublesome". Also, the necessity for game elements was not introduced leading to the comment "I would like to see others' status," and so on.

As for functions users want us to improve and add, "Appearance and animation that make change of status understood intuitively", "general operation experience", and "push notification of the update information" was listed. We think that these problems are solvable by "improvement of the visualization element", "realization of a tutorial element", and "introduction of RAW."

Next, we analyzed the operation log and investigated a user's behavior regarding difficulty of actions, mutual evaluation, and goal settings.

The action currently used by this system includes its difficulty and standard required number of days as reference information. These are the numerical values determined by the questionnaire for students in our laboratory.

The frequency graph of the average of the self-assessment for the difficulty of an action is shown in Figure 14. As a result, since an action with low difficulty has a high average score and an action with high difficulty has a low average score, it is thought that the difficulty is set up correctly on the whole. On the other hand, in spite of having to set up the action, action that was ended without self-assessment also exists. The operation $\log$ showed that only B4 students behaved in this way. It is considered that lack of foresight led to such as act for an inexperienced B4 student. As for the solution, we consider that raising an alert for too many hard actions based on the activity history of the student who performed the same action in the past would be feasible.

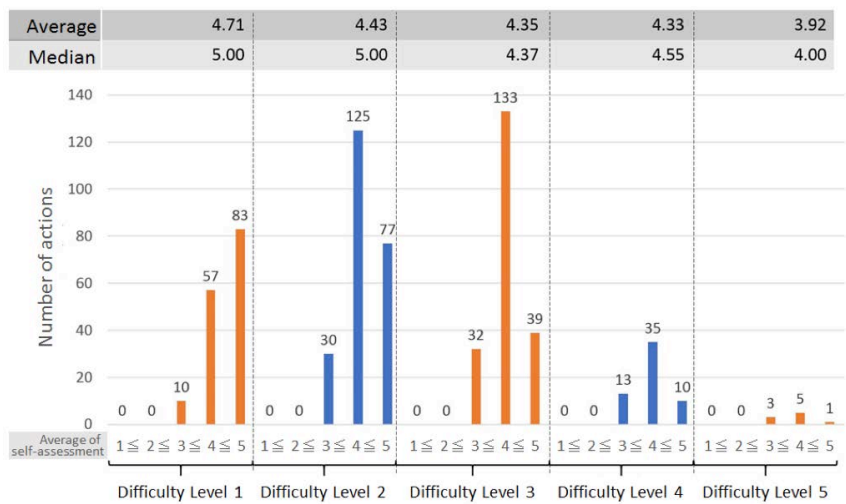

Figure 14. Score frequency of actions according to difficulty

Although three types of stamps were prepared for the mutual evaluation, the usage rate of each stamp within the experimental period is $77 \%$ "Like!", $21 \%$ "Great!", and 2\% "Thanks!". "Like!" is a common notation in SNSs, such as Facebook and Twitter, and it is expected to have been easily pushed by students. On the other hand, the stamps of "Great!" and "Thanks!" are greatly dependent on the result of the content of others' activity and mutual help. Therefore, the design of the presentation of the memo regarding 
the content of activity is needed at the time of displaying the interface regarding a mutual evaluation. However, since it is also a matter in connection with privacy, the restraint of limiting when a user expects an active assessment by the others is important for the display of memos.

We analyzed the relationship between the action including selfassessment and the next action. When the next action was set up within 5 minutes, users had set up the next action in many cases within the same activity in which the first action was performed and self-assessment was contained. On the other hand, when it had taken 5 minutes or more to set up the next action, the following action was at a distant location on the research activity map in many cases. It is considered that system improvement that can smoothly perform action settings based on a micro viewpoint and activity selecting by bird's-eye view are required. Moreover, as a different way for appropriately finding the action that should be performed next, we think that recommendation of the next action based on research activity logs would be effective.

\section{SUMMARY AND FUTURE TASKS}

In this research, we developed and introduced the research activity concierge as a comprehensive gamification platform for general research activity. As a result of analyzing activity logs, we found that students' research activities were more active. Moreover, as a result of the questionnaire, we also found that the motivation of B4 students was improved. These results were especially apparent in inexperienced students recently assigned to the laboratory.

A future task is to verify the effectiveness of our system through all the research activities. As for other tasks, a setup of elements other than goals, visualization, and rules in the gamification framework would be valuable. In particular, the design element that includes rewards and the social element that promotes competition are important as elements that raise extrinsic motivation.

\section{ACKNOWLEDGMENTS}

This work was supported by JSPS KAKENHI Grant Number $15 \mathrm{~K} 01066$.

\section{REFERENCES}

[1] Deterding, S., Dixon, D., Khaled, R., and Nacke, L. (2011, September). From Game Design Elements to Gamefulness: Defining "Gamification." In Proceedings of the 15th International Academic MindTrek Conference: Envisioning Future Media Environments. MindTrek'11. 9-15.

[2] Werbach, K., Hunter, D. 2012. For the Win: How Game Thinking Can Revolutionize Your Business. Wharton Digital Press.

[3] Cronk, R. 2012. Using Non-interactive Games to Increase Student Engagement and Participation in Class Discussion. In Proceedings of World Conference on Educational Multimedia, Hypermedia and Telecommunications. EDMEDIA'12. 311-315.
[4] Kotini, I. and Tzelepi, S. 2015. A Gamification-Based Framework for Developing Learning Activities of Computational Thinking. Gamification in Education and Business. Springer International Publishing. 219-252.

[5] Bodnar, C. A. and Clark, R. M. 2014. Exploring the Impact Game-based Learning Has on Classroom Environment and Student Engagement within an Engineering Product Design Class. In Proceedings of the Second International Conference on Technological Ecosystems for Enhancing Multiculturality. TEEM'14. 191-196.

[6] Ohira, S., Kawanishi, K., and Nagao, K. 2014. Assessing Motivation and Capacity to Argue in a Gamified Seminar Setting. In Proceedings of the Second International Conference on Technological Ecosystems for Enhancing Multiculturality. TEEM'14. 197-204.

[7] González, C., Mora, A. and Toledo, P. 2014. Gamification in Intelligent Tutoring Systems. In Proceedings of the Second International Conference on Technological Ecosystems for Enhancing Multiculturality. TEEM'14. 221-225.

[8] Ohira, S., Sugiura, K. and Nagao, K. 2015. Proposed Framework for Gamifying Research Activities. In Proceedings of the Second International Conference on Technological Ecosystems for Enhancing Multiculturality. TEEM'15, 245-250.

[9] Wong, L.-H., Chan, T.-W. Chen, Z.-H., King, R. B. and Wong, S. L. 2015. The IDC Theory: Interest and the Interest Loop. In Proceedings of the 23rd International Conference on Computers in Education. ICCE2015, 804-813.

[10] García-Peñalvo, F. J., Blanco, Á. F., Sein-Echaluce, M. L. 2015. Educational Innovation Management. A Case Study at the University of Salamanca. In Proceedings of the Second International Conference on Technological Ecosystems for Enhancing Multiculturality. TEEM'15, 151-158.

[11] Ozono, T., and Sintani, T. 2002. P2P based Information Retrieval on Research Support System Papits. In Proceedings of the IASTED International Conference on Artificial and Computational Intelligence. 49-50.

[12] Kiah, M. M., Zaidan, B. B., Zaidan, A. A., Nabi, M., and Ibraheem, R. 2014. MIRASS: Medical Informatics Research Activity Support System using Information Mashup Network. Journal of medical systems. 38. 4. 1-15.

[13] Miyadera, Y., Nakamura, S., Nanashima, T., and Yokoyama, S. 2008. LabChart: A Support System for Collaborative Research Activities in University Laboratories and its Practical Evaluations. In Information Visualisation, 2008. IV'08. 12th International Conference. 169-178.

[14] Koyama, O. and Katsuyama, Y. 2006. Design and Performance Analysis of Unified Education and Research Activity Support Systems over WWW. Journal of Innovative Computing, Information and Control. 2. 4. 807-818. 